This item was submitted to Loughborough's Research Repository by the author.

Items in Figshare are protected by copyright, with all rights reserved, unless otherwise indicated.

\title{
Online Electrochemical Impedance Spectroscopy (EIS) estimation of a solar panel
}

PLEASE CITE THE PUBLISHED VERSION

http://dx.doi.org/10.1016/j.vacuum.2017.01.011

PUBLISHER

(C) Elsevier

VERSION

AM (Accepted Manuscript)

\section{PUBLISHER STATEMENT}

This work is made available according to the conditions of the Creative Commons Attribution-NonCommercialNoDerivatives 4.0 International (CC BY-NC-ND 4.0) licence. Full details of this licence are available at: https://creativecommons.org/licenses/by-nc-nd/4.0/

\section{LICENCE}

CC BY-NC-ND 4.0

\section{REPOSITORY RECORD}

Varnosfaderani, Mina Abedi, and Dani Strickland. 2019. "Online Electrochemical Impedance Spectroscopy (EIS) Estimation of a Solar Panel”. figshare. https://hdl.handle.net/2134/24946. 


\title{
Online Electrochemical Impedance
}

\section{Spectroscopy (EIS) Estimation of a Solar Panel}

\author{
Mina Abedi Varnosfaderani and Dani Strickland \\ Engineering and Applied Science Department at Aston University, Birmingham, UK \\ (E-mail: abedivam@aston.ac.uk,d.strickland@aston.ac.uk)
}

\begin{abstract}
Electrochemical Impedance Spectroscopy (EIS) techniques are useful tools for being able to look at the characterisation of solar panels under different conditions and/or with different material components. However EIS analysis is mostly undertaken offline with bespoke equipment. This paper describes a method of undertaking EIS measurement on-line without the use of additional equipment by manipulating the control of the solar panel connected dc-dc power electronic converter. The power electronic control is used to inject an additional low-frequency signal into the circuit and then sweep this frequency across a range to replicate the functionality of the EIS without the need for a separate excitation circuit while maintaining full operational functionality. This paper describes the methodology and presents some experimental results compared with EIS results under the same conditions to illustrate the concept.
\end{abstract}

Keywords - Solar Panel, dc-dc converters, frequency analysis, electrochemical impedance spectroscopy (EIS)

\section{NOMENClATURE}

$f_{s} \quad$ switching frequency

$\mathrm{Hz}$

$T_{s} \quad$ Switching frequency time period

S

$f_{o} \quad$ Low-frequency spectroscopy waveform

$\mathrm{Hz}$

$T_{o} \quad$ Time period of low-frequency waveform

S

$d(t) \quad$ DC-DC Converter duty cycle at time $\mathrm{t}$ 


$\begin{array}{lll}d_{a v} & \text { Average duty cycle } & \\ d_{m} & \text { Duty cycle of } \mathrm{m}^{\text {th }} \text { pulse } & \\ N_{p} & \text { Number of high frequency pulses per low-frequency cycle } & \\ \tau_{m} & \text { The width of the } \mathrm{m}^{\text {th }} \text { pulse } & \mathrm{s} \\ t_{d t m} & \text { The time delay of the } \mathrm{m}^{\text {th }} \text { pulse } & \mathrm{s} \\ v_{m} & \mathrm{~m}^{\text {th }} \text { Sawtooth wave maximum value } & \mathrm{A} \\ u_{m} & \mathrm{~m}^{\text {th }} \text { Sawtooth wave minimum value } & \mathrm{A} \\ V_{\text {solar }} & \text { Solar panel voltage } & \mathrm{V} \\ V_{d c} & \text { DC-DC converter output voltage } & \mathrm{V} \\ P_{\text {in }} & \text { Input Power } & \mathrm{W} \\ P_{\text {out }} & \text { Output Power } & \mathrm{W} \\ A_{d} & \text { Offset amplitude } & \end{array}$

\section{INTRODUCTION}

Electrochemical impedance spectroscopy (EIS) is a diagnostic method to describe and to evaluate the behaviour of electrical element reactions. Electrochemical impedance spectroscopy measurements can be undertaken through a couple of different methods; these include analogue analysis and processing of systems in the time and/or frequency domain using bespoke EIS equipment or digital computation [1]. The main basis for the method is to measure the frequency response of a test piece to understand how its impedance changes over the frequency domain. An EIS test is usually performed by applying a small AC excitation signal (AC potential or current signal) into the electrochemical cell and measuring the correspondence voltage (or current) response. The impedance value is then calculated from the transfer function of the input and output signals as:

$$
Z(\omega)=\frac{V(\omega)}{I(\omega)}
$$


Typically EIS measurement is undertaken off line and using bespoke equipment. The transfer function is then used to produce an equivalent circuit of the panel which can be used to understand how these parameters change with condition.

Publications on EIS measurement of solar panels have looked into the impact of different materials (eg different electrolyte alloys) on solar cell impedance [2], the impact of different connection mechanisms (eg series vs parallel) [3], the impact of temperature [4-5] and the impact of outdoor use on degradation [5-8]. These papers typically produce EIS plots which are used to determine equivalent circuit parameters and show variation with time. By way of illustration, Fig. 1 is a high level sketch of the EIS Nyquist plot shapes previously obtained in literature [4-8] showing how the EIS parameters for dye-sensitized cells may be expected to change with condition as indicated by the arrows.

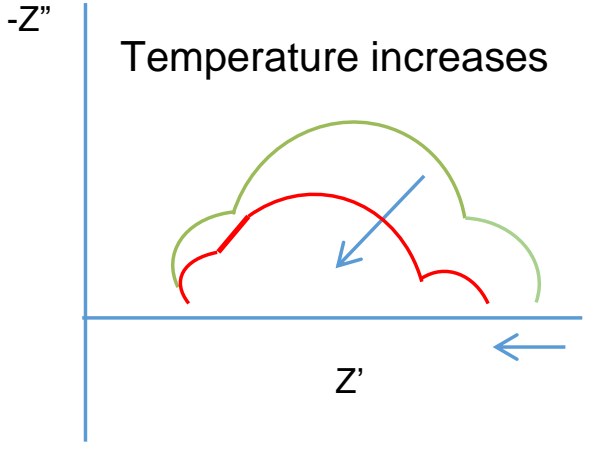

a)

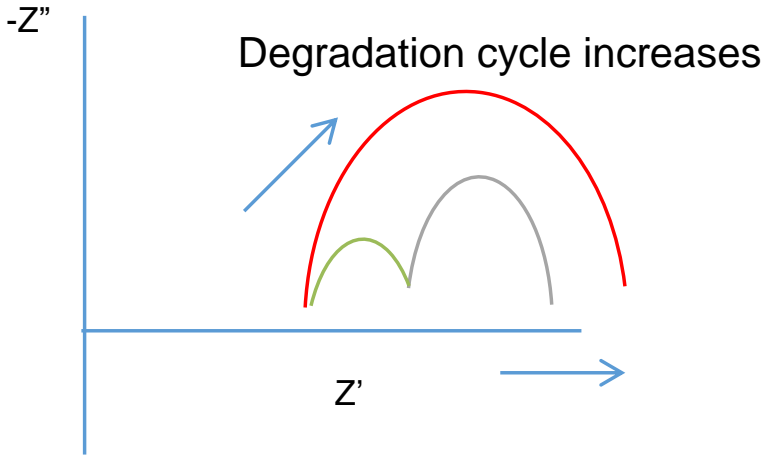

b)

Fig. 1. Sketch of previously published change in EIS shape with temperature [4-5] (a) and degradation [5-8] (b)

EIS is more common in the field of battery analysis than it is in the field of solar cell analysis. However even with battery work, EIS tends to be undertaken offline. Some attempts to replicate an EIS method on-line have been undertaken [9-12]. Reference [10] uses a half bridge circuit to excite a battery, while Reference [9] measured the impedance of the battery by using a motor inverter with the additional possibility of using an external excitation circuit to generate the low frequency excitation required to look at battery impedance. However the key disadvantages of 
both these methods is that the excitation current is at the fundamental frequency of the converter. So, the frequency cannot be swept across a range of values without a separate excitation circuit. Reference [11] introduces a method of low frequency harmonics injection to estimate the impedance and State of Charge (SOC) of the batteries as a proof of concept with no analysis or insight. State of Charge (SOC) of the battery, in this instance, is defined as the percentage energy available in a battery system for discharge with reference to the total useable capacity of the battery. Reference [12] continued this work and looked at EIS measurement using this technique on a battery system.

This paper looks at the method used by [11-12] in more analytical detail against more traditional operation and investigates how this can be translated for use in conjunction with a solar panel.

This method uses the dc-dc power electronic converter, which connects the solar panel to an inverter to the electrical grid system or to a dc load to inject a low-frequency signal and then sweep this frequency across a range to replicate the functionality of the EIS without a need for a separate excitation circuit. The solar voltage and current are measured and used to determine the harmonic impedance. The technique is conducted on-line with the solar system under normal operation. This paper includes a description of the background derivation of the necessary equations needed to define the operation of the converter in boost mode while giving insight into new design parameters such as inductor ripple current calculation in section III. Section IV looks at both modelled and experimental results showing real time operational characteristics and EIS generated results validated against off-line measurements. Section VI concludes the paper with a discussion of the methodology and the further research needed before this method can be adopted.

\section{LOW-FREQUENCY IMPEDANCE ESTIMATION METHOD}

The key requirement of this method is that it has to generate a low-frequency waveform of variable frequency while at the same time producing a high-frequency pulse train to boost or 
buck a voltage using the hardware already in-situ. This work is based on using the hardware available in a standard dc-dc converter topology as shown in Fig. 2.

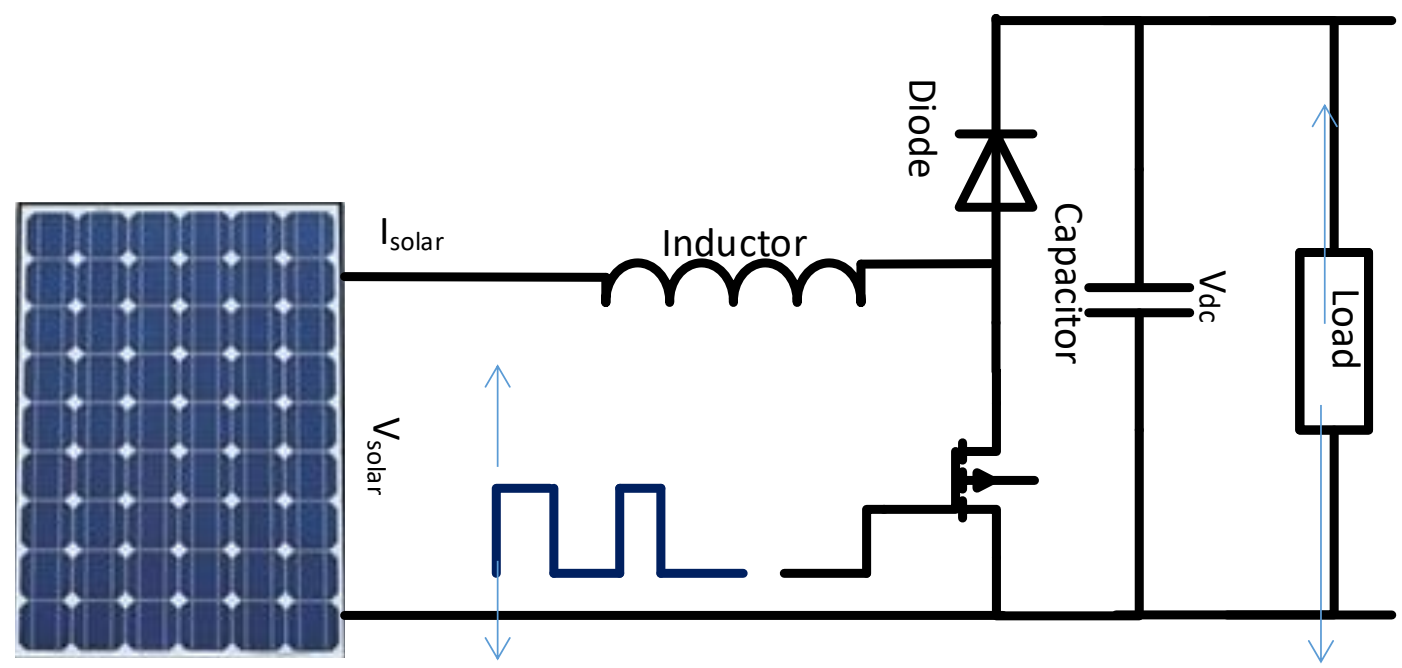

Fig. 2. DC-DC Converter Topology for Solar panel Impedance measurement

One method of injecting a low-frequency waveform is to use the power electronic converter to inject low-frequency pulses in conjunction with the normal higher frequency pulses associated with boost operation. This can be performed by varying the duty cycle of the PWM signal of the switching component of the converter. To do this the average duty cycle needs to be maintained, but a small component representing a low-frequency component has been added to the duty cycle as shown in (2):

$$
d(t)=d_{a v}+A_{d} \cos \left(\omega_{o} t\right)
$$

where $d_{a v}$ is average duty cycle, $A_{d}$ is the offset amplitude and $\omega_{o}$ is the low-frequency component.

The higher pulse signal is switched with a switching frequency of $f_{s}$ and switching time period of $T_{S}$ and the low-frequency component is varied with a low-frequency $f_{o}$ with a time period of $T_{o}$. Therefore, the number of pulses in one low-frequency cycle can be defined as:

$$
N_{p}=\frac{T_{o}}{T_{S}}
$$


To assist with analysis at this time, it is assumed that $\mathrm{N}_{\mathrm{p}}$ is an integer, that the pulse is switched on at time $\mathrm{t}=0$ and that each pulse is switched on at the start of every switching period, $T_{S}$ and stays on for a period defined by $\tau_{m}=d_{m} T_{s}$ where $\mathrm{m}$ is the $\mathrm{m}^{\text {th }}$ pulse in $\mathrm{N}_{\mathrm{p}}$ as shown in Fig. 3 and $d_{m}$ is the duty cycle from (2) and equal to $d_{m}=d_{a v}+A_{d} \cos \left(2 \pi m / N_{p}\right)$. The current harmonics can be considered by application of Fourier series analysis of the waveform similar to that in reference [12-13] by considering $\tau_{m}$ as the width of the $\mathrm{m}^{\text {th }}$ pulse, and $t_{d t m}$ as the relative time shift of the $\mathrm{m}^{\text {th }}$ function from $\mathrm{t}=0$ as shown in Fig 3.
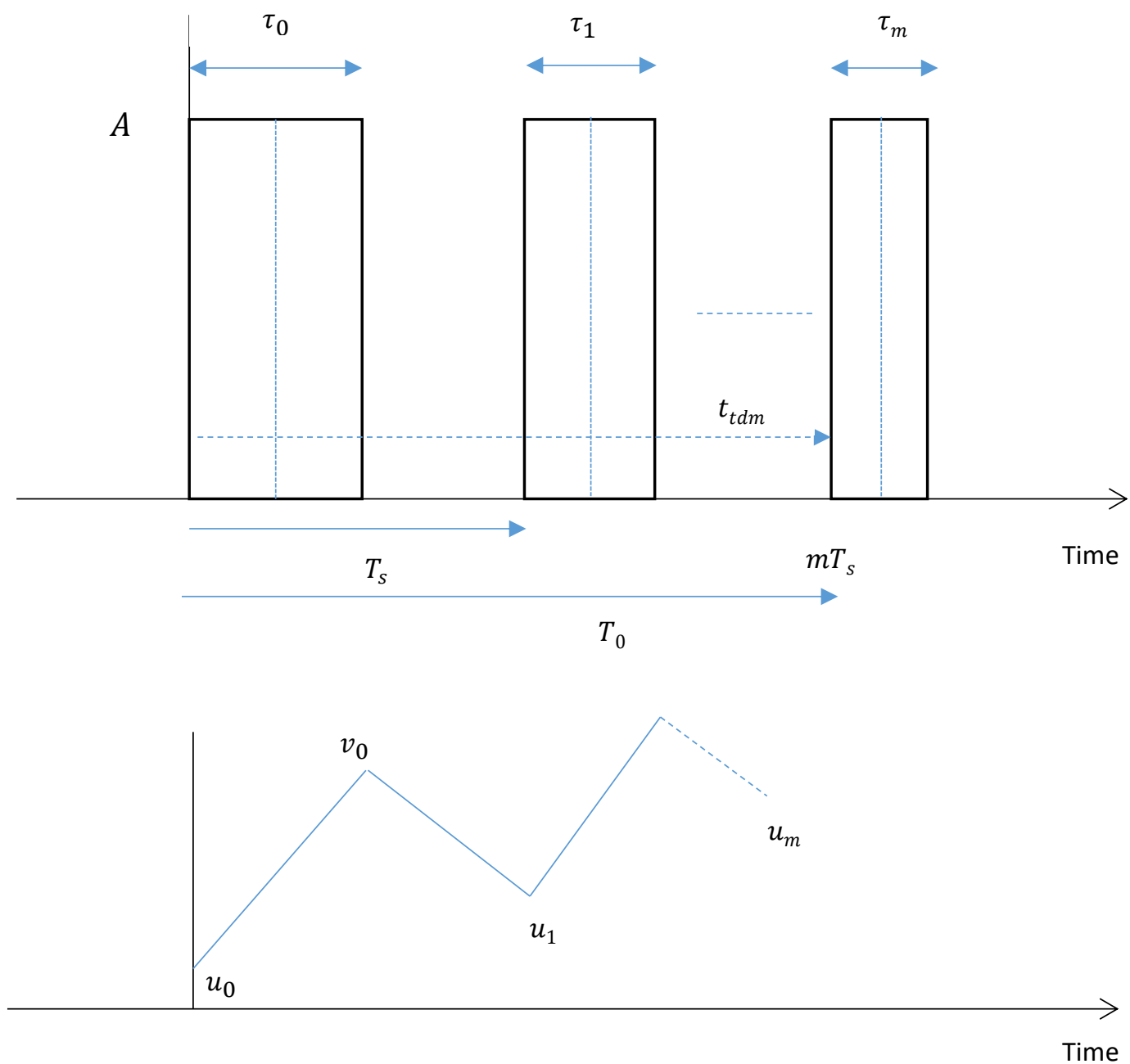

Fig. 3. Definition of variables used in the gate drive pulse and sawtooth waveform for Fourier analysis

This analysis can be extended to the current saw tooth waveform seen by the solar panel. The first function is a periodic sawtooth function with a period of $T_{o}$ and duration $\tau_{0}$ from $u_{o}$ to $v_{0}$. 
The second function is a periodic sawtooth wave with the opposite slope with a period of $T_{o}$ but shifted with respect to the first waveform by $d_{m} T_{s}$ from $v_{o}$ to $u_{1}$. The on and off current slopes of the saw tooth waveform can be calculated from the differential equations for the circuit as:

$$
\begin{aligned}
& v_{m}-u_{m}=\frac{1}{\tau_{m} L} V_{b a t} d_{m} T_{s} \\
& u_{m+1}-v_{m}=\frac{1}{\left(T_{s}-\tau_{m}\right) L}\left(V_{b a t}-V_{d c}\right)\left(T_{s}-d_{m} T_{s}\right)
\end{aligned}
$$

These theoretical values of circuit harmonics can be used to numerically cross check and validate the measured harmonics from the experimental setup including the measured low frequency component. The low frequency range, which gives most information about the solar behaviour in this paper is from $500 \mathrm{~Hz}$ to $90 \mathrm{kHz}$. The switching frequency was therefore set to $100 \mathrm{kHz}$.

Using an average duty cycle means that the boost ratio is identical to a fixed duty cycle wave of the same average duty cycle. However, the peak to peak ripple compared to a fixed boost ratio varies as shown in Fig. 4.

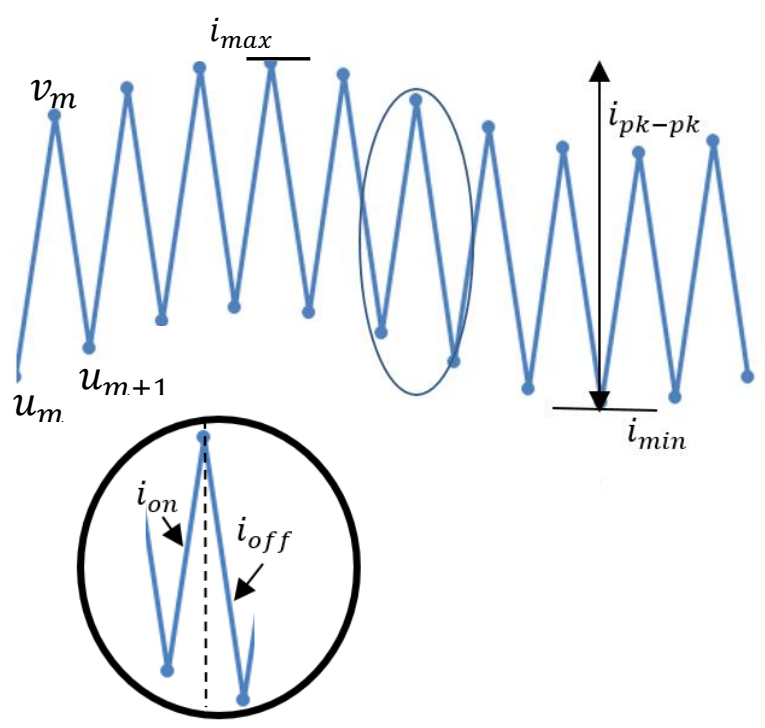

Fig. 4. Converter current waveform in continuous mode

This can be approximated to [12]:

$$
v_{\text {max }}-u_{\text {min }} \approx 1+\frac{A_{d} N_{p}}{d_{a v}\left(1-d_{a v}\right) \pi}
$$


The ripple current increases with $A_{d}$ as expected. A trade off therefore exists between the magnitude of the ripple on the duty cycle and the effectiveness of the instrumentation to measure the maximum and minimum current and voltage ripple on the solar panel. In addition it is necessary to ensure that the inductor can deal with this extra ripple. The analysis above assumes negligible resistance and future work will require the ripple to be modified downwards to take account of the resistance in the circuit.

\section{LOW-FREQUENCY IMPEDANCE ESTIMATION MODELLING}

To help validate the methodology, it is useful to simulate the circuit and compare the output waveforms with those generated theoretically and experimentally.

\section{A. Solar panel Representation}

To undertake circuit simulation the impedance of the solar panel for use in the model was found by EIS measurement and represented in a MATLAB simulation as an equivalent circuit. This was done at two operational conditions as shown in Fig 5. Point A was chosen as an alternative operating point by way of comparison. This point also lies on a more linear part of the I-V curve, such that a small perturbation of current will result in a linear perturbation of voltage about this operating point [14].

An off-the shelf multicomp polycrystalline $800 \mathrm{~mW}$ Solar Panel was used in these experiments. The solar equivalent circuit parameters were obtained using an EIS impedance analyser (solatron 1260 and 1287) as shown in 


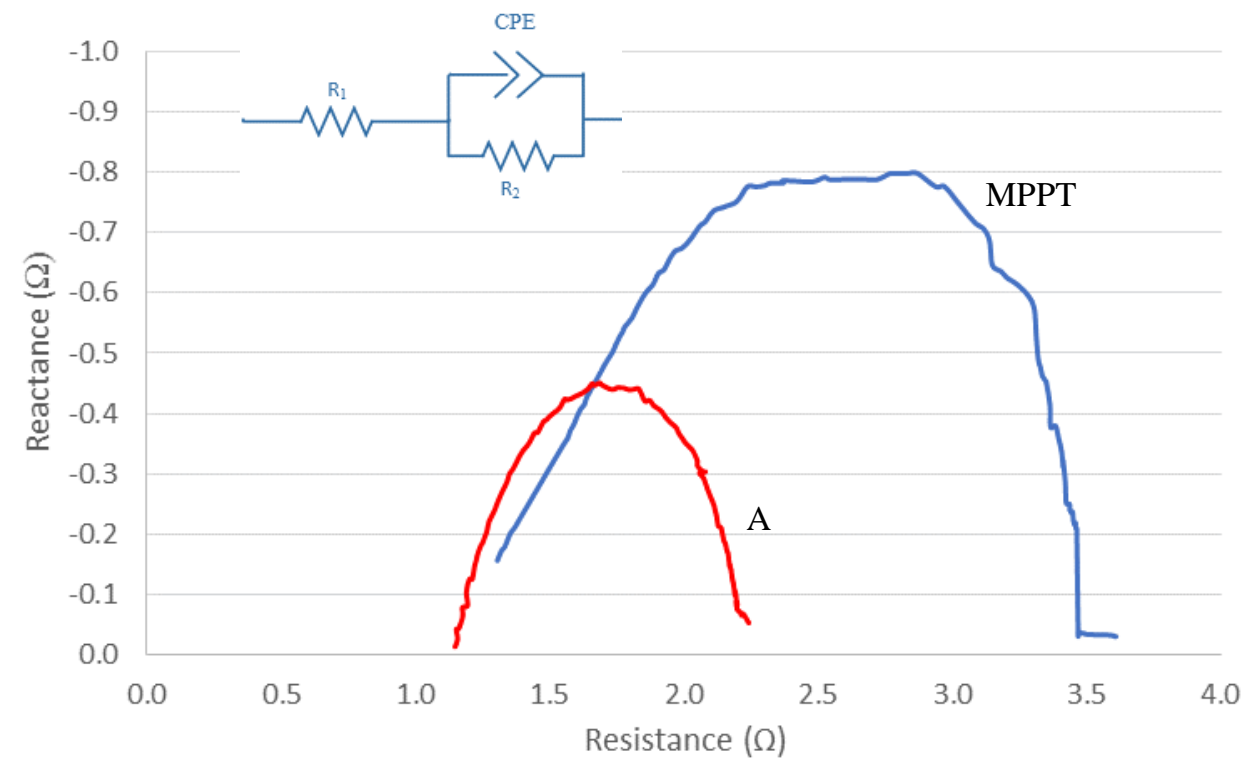

Fig. 6. Solar panel EIS impedance plot at the two operational conditions and the equivalent circuit model

. The impedance of the batteries was excited by $73 \mathrm{~mA}$ Ac current and a dc discharge current of $140 \mathrm{~mA}$ in the frequency interval of $(500 \mathrm{~Hz}$ to $100 \mathrm{kHz})$. The dc discharge current value was chosen to match the inductor current of the converter under later experimental conditions. 


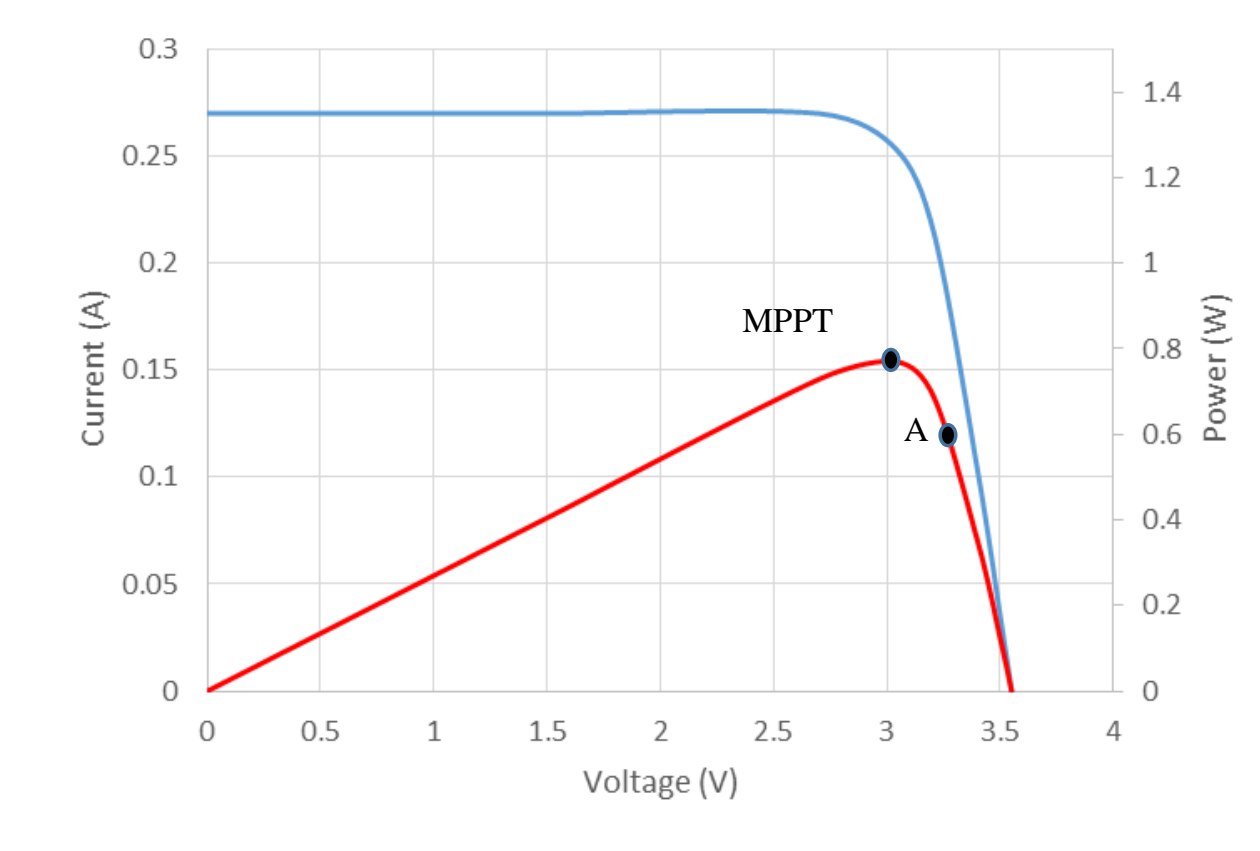

Fig. 5. Solar Panel current (blue) and power rating (red) characteristic

The Nyquist diagram of the solar panel comprises a semicircle (represented as parallel connection of resistor and capacitor shown as a parallel resistor and constant phase element, CPE, due to impurity in capacitor behaviour [14]) and a series resistor [3, 15]. Table I shows the EIS derived values of these components. 


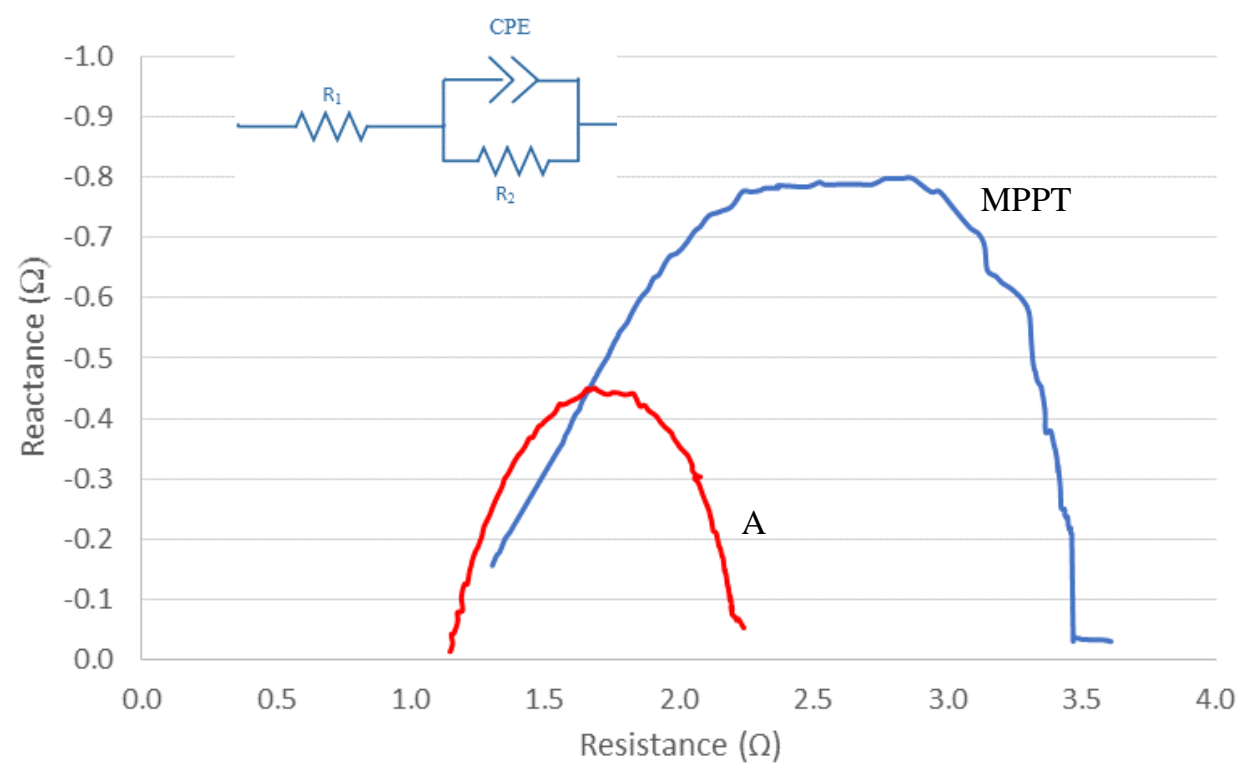

Fig. 6. Solar panel EIS impedance plot at the two operational conditions and the equivalent circuit model

Table I

Solar panel Equivalent Circuit Model component specifications

\begin{tabular}{|c|c|}
\hline Components & Photovoltaic solar panel \\
\hline MPPT operation & 1.372 \\
\hline$R_{1}(\Omega)$ & 2.26 \\
\hline$R_{2}(\Omega)$ & $8.67 \mathrm{e}-5$ \\
\hline$C P E_{1}(\mathrm{~F})$ & \\
\hline$R_{1}(\Omega)$ & 1.163 \\
\hline$R_{2}(\Omega)$ & 1.077 \\
\hline$C P E_{1}(\mathrm{~F})$ & $6.404 \mathrm{E}-5$ \\
\hline
\end{tabular}

\section{B. Circuit representation}

In this paper, the panel is considered as an ideal solar cell. In order to generate a set of comparable simulation results the PV panel from 


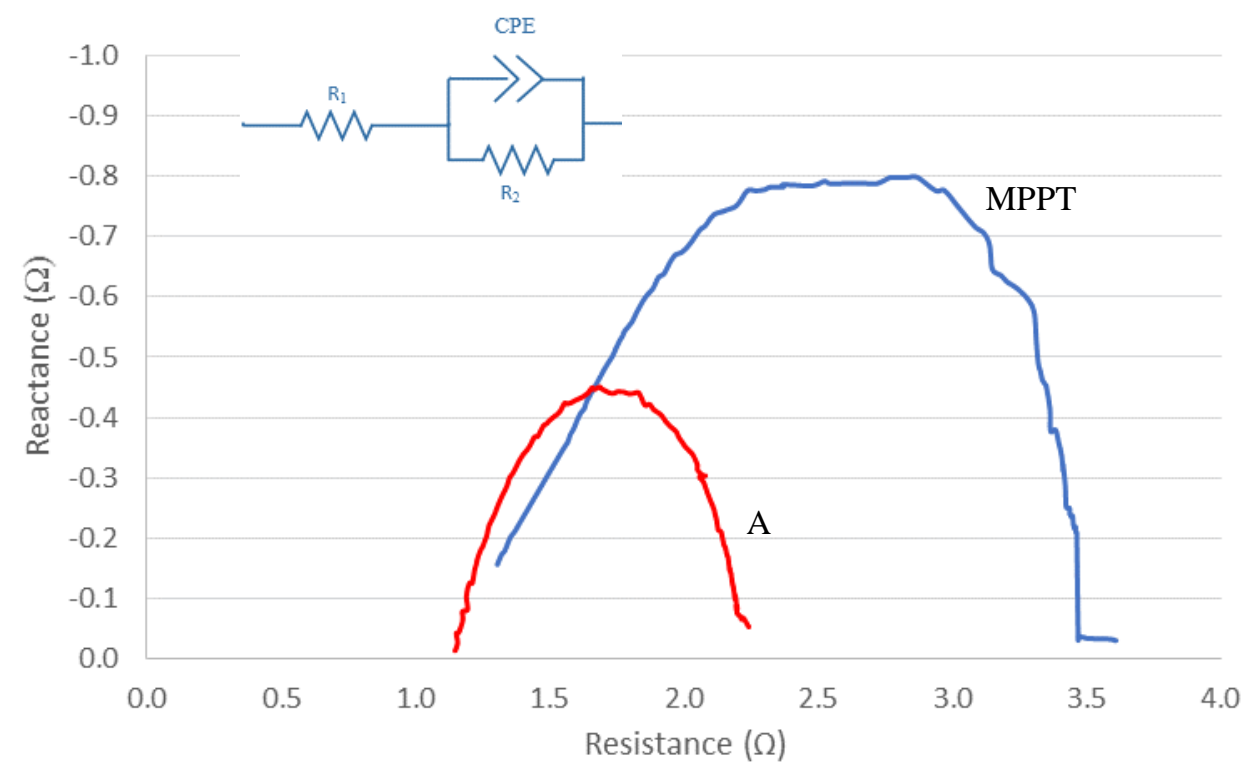

Fig. 6. Solar panel EIS impedance plot at the two operational conditions and the equivalent circuit model

and the boost converter from Fig. 1 are modelled using Matlab Simulink software as shown in Fig. 7. The component values in the simulation model are based on the experimental hardware components. The component values of the converter were selected to ensure that for the purposes of this paper the converter operates in continuous mode at a duty cycle of 0.5 at $100 \mathrm{kHz}$ frequency.

The $0.8 \mathrm{~W}$ photovoltaic solar panel was operated with an output voltage of $3.4 \mathrm{~V}$. The dc-dc converter was used to boost this to $6.8 \mathrm{~V}$ with a corresponding load output current of $6.8 \mathrm{~mA}$. The hardware setup was set to always operate the converter in continuous mode with a boost ratio of 2. Converter components were calculated according to this assumption. An HER204G Rectifier Diode with maximum 2A forward was used. The specifications of the components are summarised in Table II. 


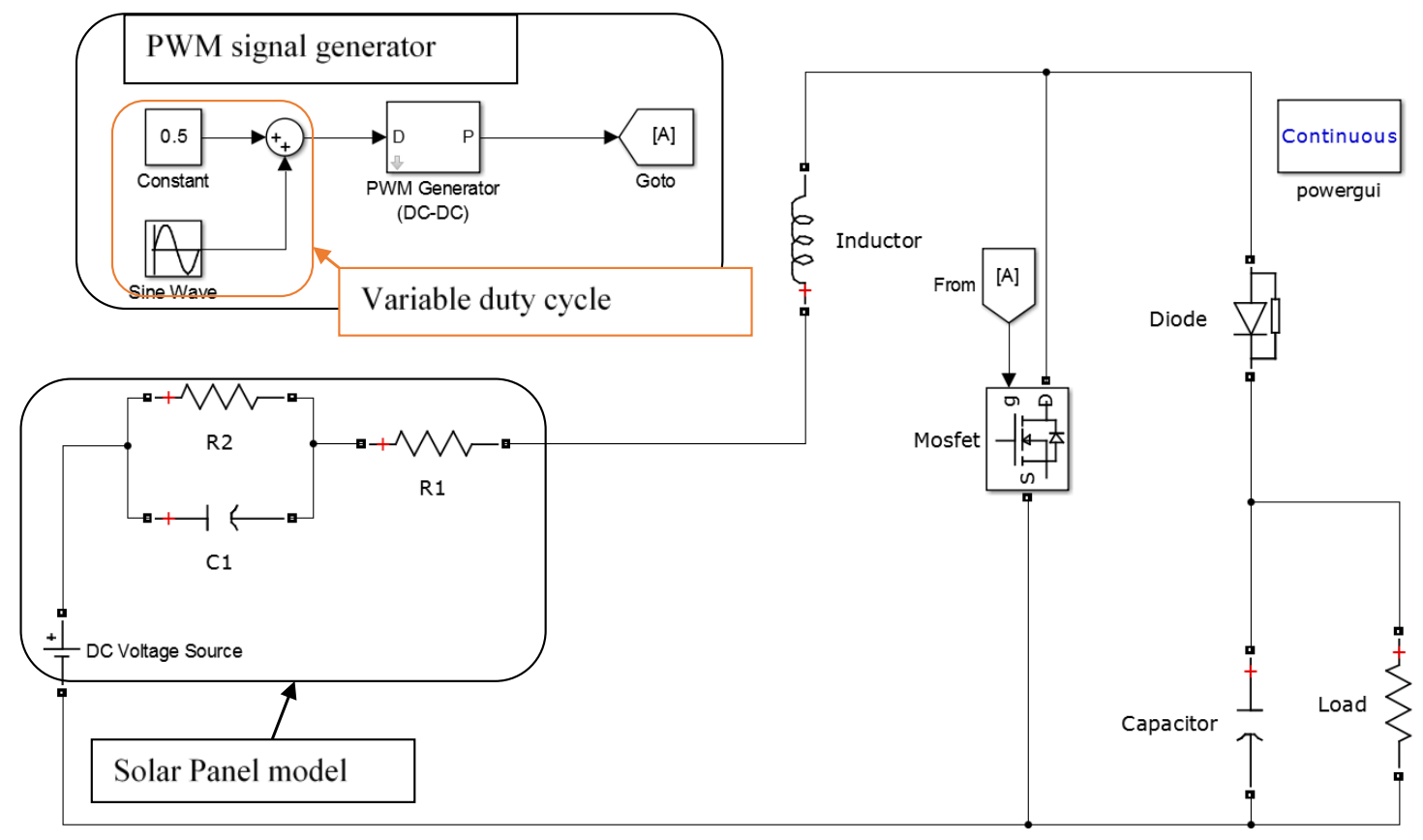

Fig. 7. MATLAB simulation model of solar panel with variable duty cycle

Table II

Boost converter component specifications

\begin{tabular}{|l|l|}
\hline Components & Specifications \\
\hline Inductance & $360 \mu \mathrm{H}, 20 \mathrm{~A}$, Toroidal \\
\hline Capacitance & $470 \mu \mathrm{F}, 16 \mathrm{~V}$ Electrolytic \\
\hline Load & $1 \mathrm{k} \Omega$ Resistor \\
\hline Switch MOSFET & FDPF045N10A, $100 \mathrm{~V}, 67 \mathrm{~A}, 4.5 \mathrm{~m} \Omega$ \\
\hline
\end{tabular}

The switching frequency and the average duty cycle of the switching signal are set to $100 \mathrm{kHz}$ and 0.5 respectively while the low-frequency signal $f_{o}$ is varied from $500 \mathrm{~Hz}$ to $90 \mathrm{kHz}$. The system was kept within continuous mode of operation. The duty cycle was set to include a low frequency component by adjusting the duty cycle between 0.488 and 0.512 :

$$
d_{m}=0.5+0.012 \cos \left(\omega_{o} t\right)
$$




\section{EXPERIMENTAL RESULTS AND DISCUSSION}

In order to measure the impedance of the solar panel, the panel voltage and current are measured every time that the low frequency is changed. Fig. 8 shows the experimental setup used to look at on-line low-frequency impedance measurement as described above. The voltage and current were measured using a Lecroy $100 \mathrm{MHz}$ current probe and a Tektronix P2220 $200 \mathrm{MHz}$ voltage probe but ACPL- 870 voltage sensor and ACS712 current sensor measurement devices linked to the controller have also been used to get the same results. The gate drive signals were derived from an Opal-RT controller.

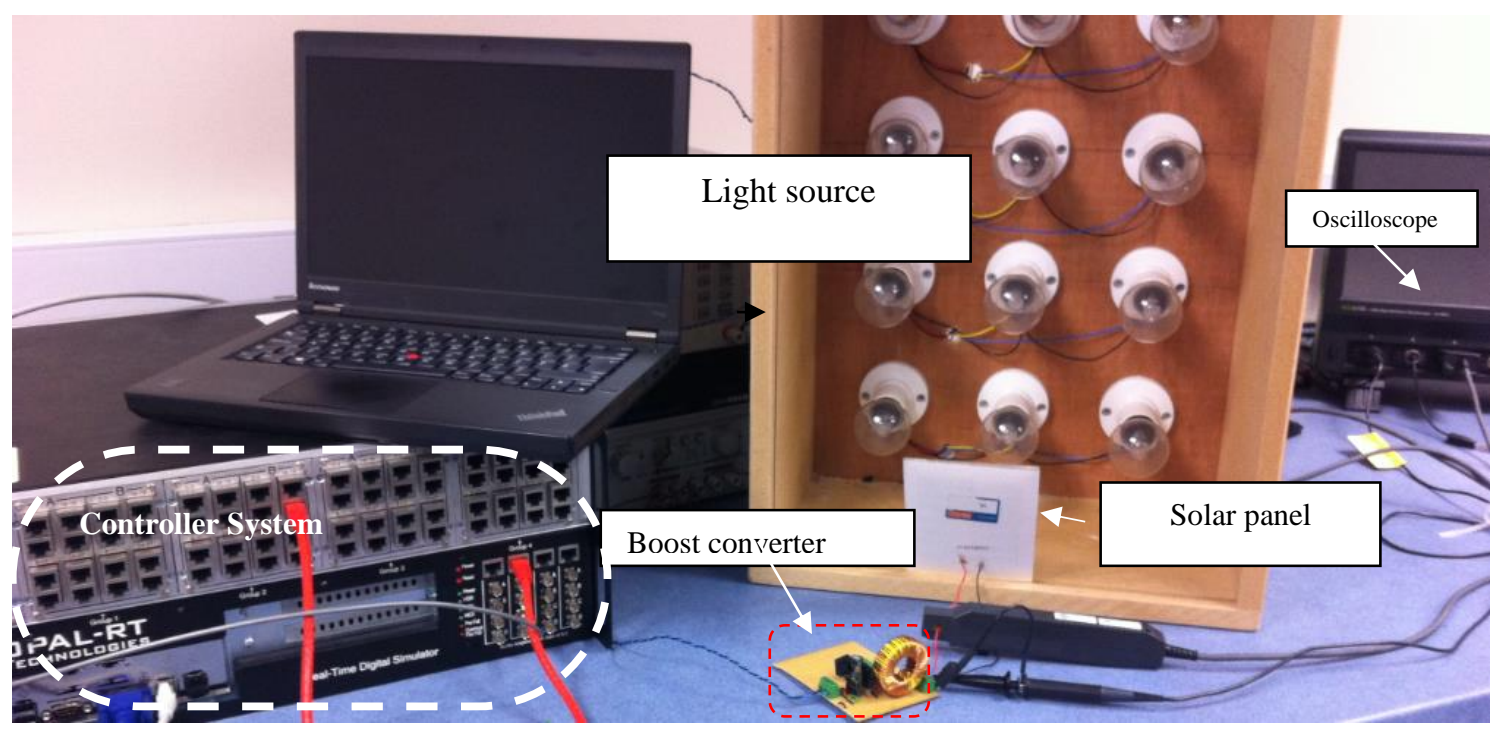

Fig. 8. Experimental Set Up

\section{A. Single low frequency}

Fig. 9 and Fig. 10 show the experimentally captured I and V waveform with a variable duty cycle including a low-frequency ripple of $10 \mathrm{kHz}$ and a fixed duty cycle. 

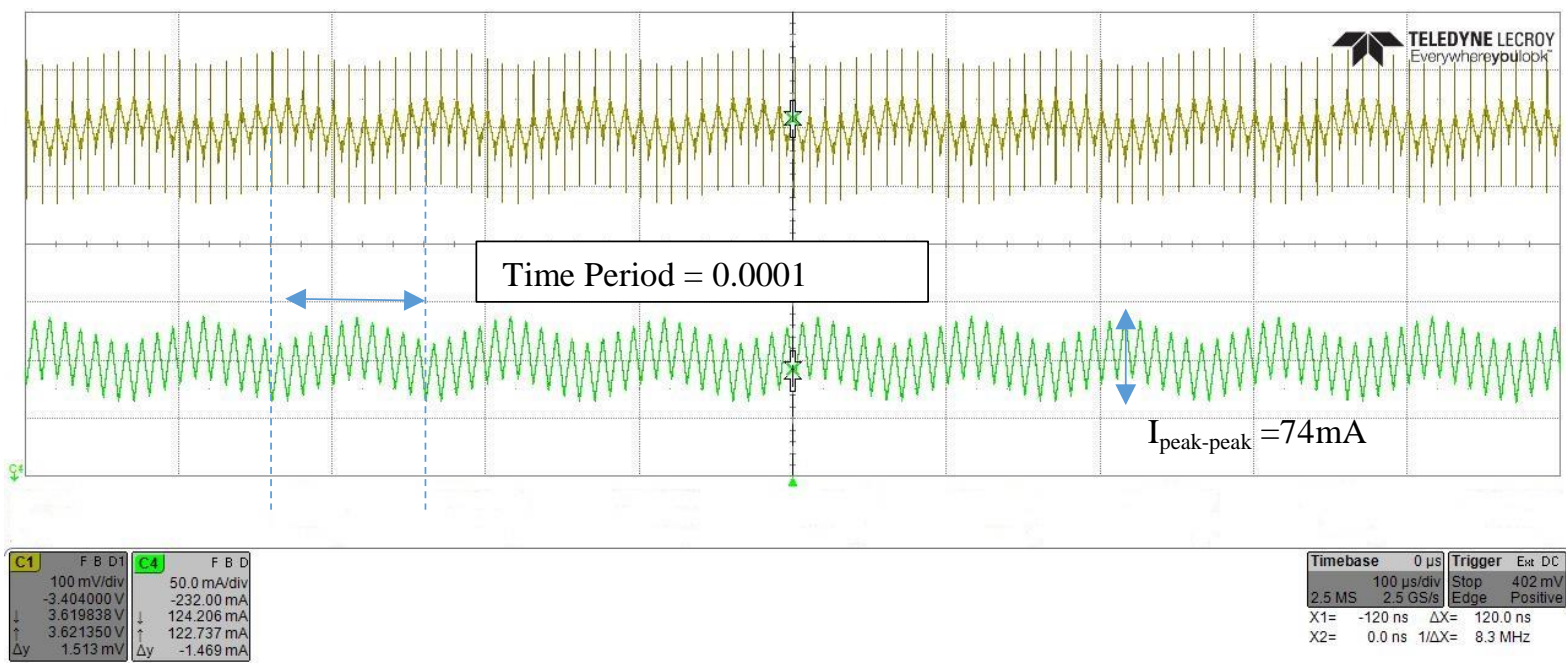

Fig. 9. Solar Current (Green) and Voltage (yellow) waveforms, the panel is excited with variable duty cycle with a low frequency component of $10 \mathrm{kHz}$
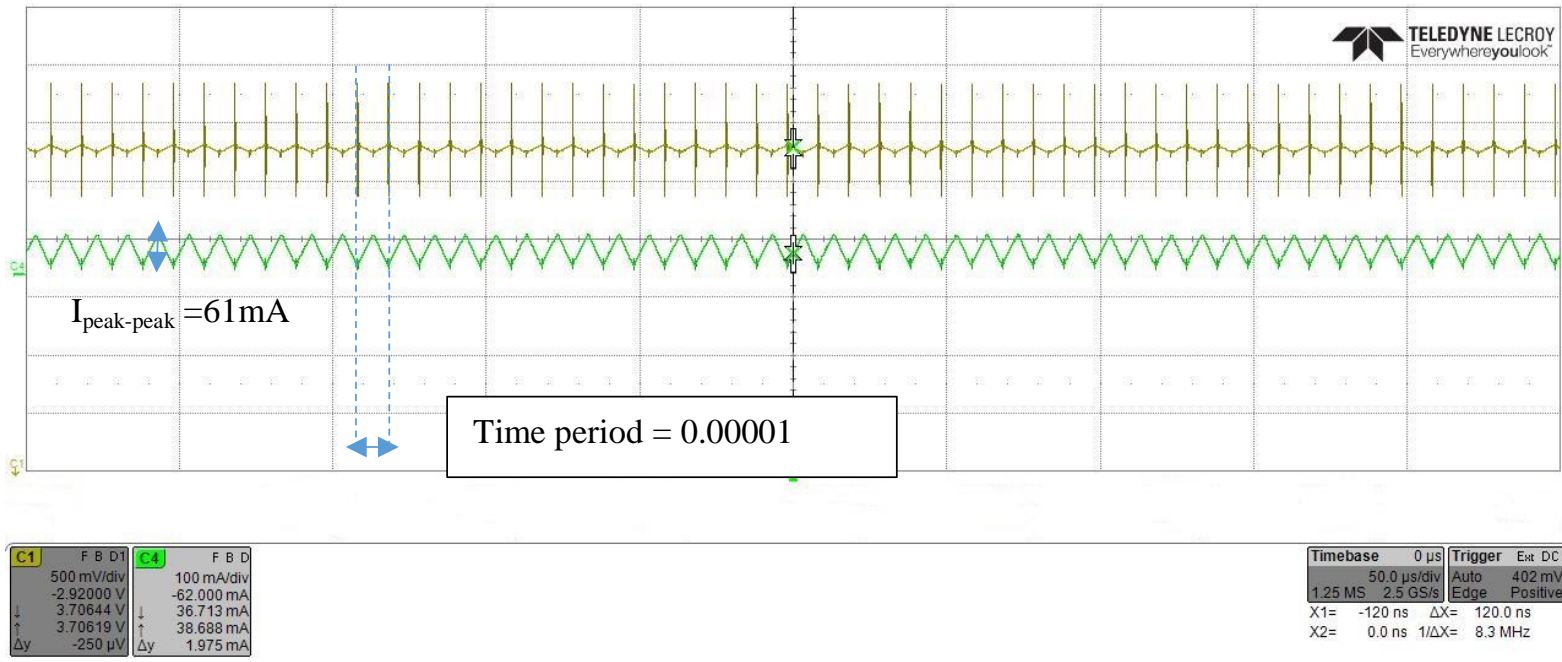

Fig. 10. Solar Current (Green) and Voltage (yellow) waveforms, the panel is excited with constant duty cycle (no low frequency ripple is included)

The experimental results show a component of low frequency ripple has been added to the solar panel increasing the peak to peak ripple. A full comparison of the key parameters using a fixed duty cycle and variable duty cycle under experimental and simulated conditions at $10 \mathrm{kHz}$ low frequency ripple are shown in Table III. Table III shows the values of the input and output current, voltage and power of the boost converter measured from simulation model and experiments. Comparison of the data shows that the simulation model of the converter is 
performing in a manner similar to the experimental data indicating a good understanding of circuit behaviour and the validity of the EIS impedance in the simulation at a single fixed frequency condition.

\section{Table III}

Comparison of fixed duty cycle with variable duty cycle at $10 \mathrm{kHz}$ effects on Current and Voltage ripple

\begin{tabular}{|c|c|c|c|c|}
\hline & \multicolumn{4}{|c|}{ Experimental } \\
\hline & \multicolumn{2}{|c|}{ Fixed Duty Cycle } & \multicolumn{2}{|c|}{ Variable Duty Cycle } \\
\hline & Average Value & \multirow{2}{*}{$\begin{array}{l}\text { Peak-Peak } \\
\text { value }\end{array}$} & Average Value & \multirow[t]{2}{*}{ Peak-Peak value } \\
\hline$P_{\text {in }}$ & $486 \mathrm{~mW}$ & & $490 \mathrm{~mW}$ & \\
\hline$I_{\text {solar }}$ & $135 \mathrm{~mA}$ & \multirow[t]{5}{*}{$61 \mathrm{~mA}$} & $140 \mathrm{~mA}$ & \multirow[t]{5}{*}{$74 \mathrm{~mA}$} \\
\hline$V_{\text {solar }}$ & $3.6 \mathrm{~V}$ & & $3.5 \mathrm{~V}$ & \\
\hline$I_{\text {load }}$ & $6.7 \mathrm{~mA}$ & & $6.9 \mathrm{~mA}$ & \\
\hline$V_{d c}$ & $7.19 \mathrm{~V}$ & & $7 \mathrm{~V}$ & \\
\hline \multirow[t]{4}{*}{$P_{\text {out }}$} & $48.17 \mathrm{~mW}$ & & $48.3 \mathrm{~mW}$ & \\
\hline & \multicolumn{4}{|c|}{ Simulation } \\
\hline & \multicolumn{2}{|c|}{ Fixed Duty Cycle } & \multicolumn{2}{|c|}{ Variable Duty Cycle } \\
\hline & Average Value & \multirow{2}{*}{$\begin{array}{c}\text { Peak-Peak } \\
\text { value }\end{array}$} & Average Value & \multirow[t]{2}{*}{ Peak-Peak value } \\
\hline$P_{\text {in }}$ & $459 \mathrm{~mW}$ & & $476 \mathrm{~mW}$ & \\
\hline$I_{\text {solar }}$ & $135.2 \mathrm{~mA}$ & $57.1 \mathrm{~mA}$ & $140.2 \mathrm{~mA}$ & $68.4 \mathrm{~mA}$ \\
\hline$V_{\text {solar }}$ & $3.4 \mathrm{~V}$ & & $3.4 \mathrm{~V}$ & \\
\hline$I_{\text {load }}$ & $6.8 \mathrm{~mA}$ & & $6.75 \mathrm{~mA}$ & \\
\hline$V_{d c}$ & $6.8 \mathrm{~V}$ & & $6.75 \mathrm{~V}$ & \\
\hline$P_{\text {out }}$ & $46.24 \mathrm{~mW}$ & & $45.88 \mathrm{~mW}$ & \\
\hline
\end{tabular}

The peak to peak current is increased due to the low frequency ripple. The increase in ripple between variable and fixed duty cycle is $20 \%$ which is slightly higher than the calculated increase from equation (6) of $15 \%$. However the conditions are not exactly equal between the 
two different duty cycles experimentally which may explain some of the difference. The lowfrequency ripple clearly shows that the low frequency harmonic has been introduced to the system. Fig. 11 shows the FFT analysis of the experimental current waveform from Fig 8 with the $10 \mathrm{kHz}$ ripple. Compared to that obtained theoretically.
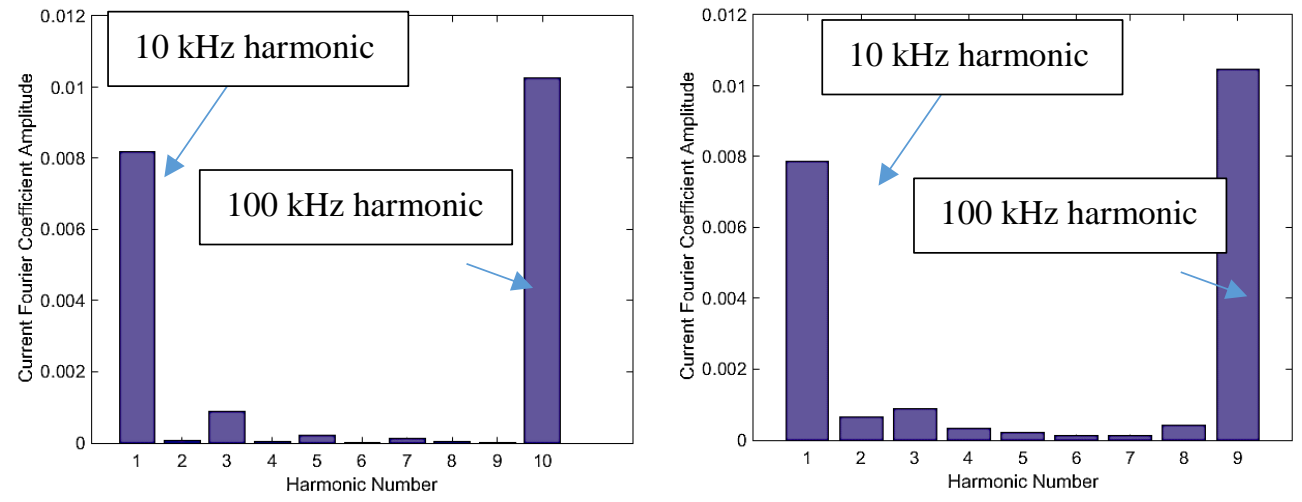

Fig. 11. Low-frequency harmonics of the solar panel current signal experimentally (left) and theoretically (right)

From equation (6), the variation of $A_{d}$ changes the amount of adding a ripple to the circuit waveforms, as it decreases the ripple values becomes smaller as shown in Fig. 12. The ripple increase above a fixed duty cycle for each condition in Fig. 12 from equation (6) is 63\% and $16 \%$ compared to experimental values of $70 \%$ and $17 \%$.
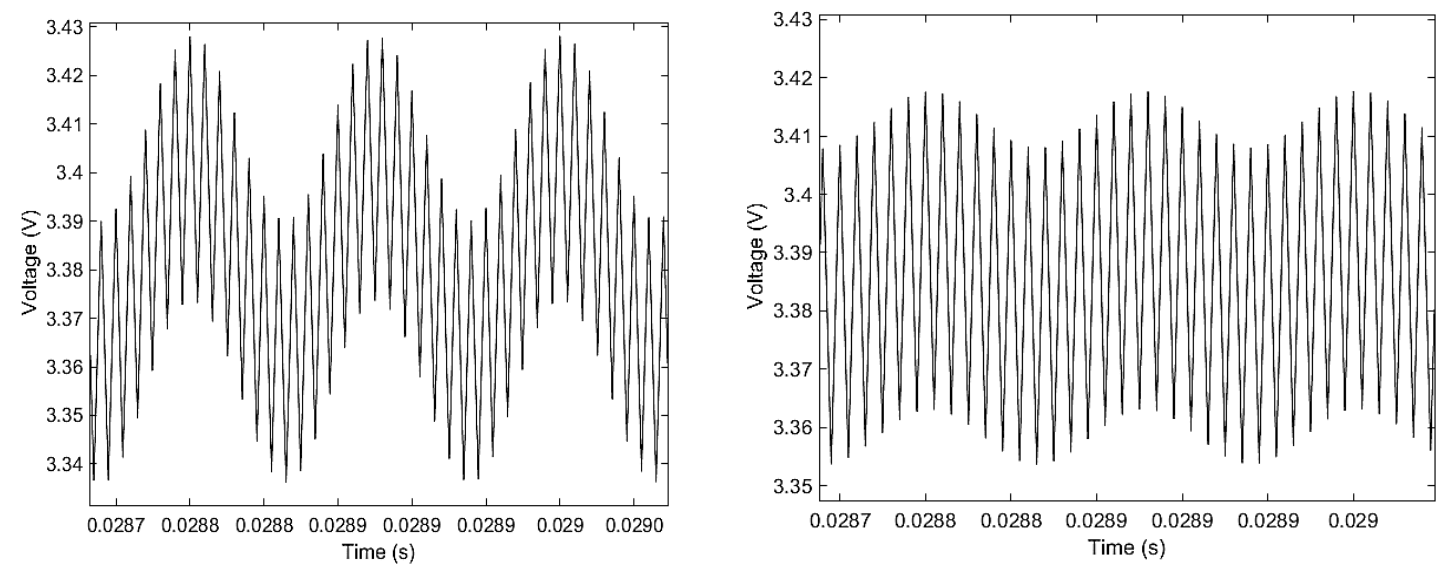

Fig. 12. Comparison of the low frequency ripple at (Left) $A_{d}=0.04$, and (Right) $A_{d}=0.01$. With $d_{a v}=0.5$ and $f_{0}=8 \mathrm{kHz}$. 


\section{B. Range of low frequencies}

The methodology was applied to a photovoltaic panel to investigate the impedance across a range of low frequencies. The low frequencies were chosen in the frequency range of $500 \mathrm{~Hz}$ to $90 \mathrm{kHz}$ to tie up with the EIS results. The tests were conducted under constant luminance with a fixed light source, of 12 individual $100 \mathrm{~W}$ tungsten bulbs in a dark room. The solar cell was operated at point A and MPPT on its operational voltage and current curve as shown in Fig. 5.

The maximum measured power of the solar panel occurs at point MPPT on the operating chart. This occurs with a load resistance of $12 \Omega$ and an equivalent power of $0.798 \mathrm{~W}$ under the same illumination as the experiments above. This is close to the published manufacturers data. The short circuit current was measured at $0.270 \mathrm{~mA}$ and the open circuit voltage was $3.6 \mathrm{~V}$.

To verify the proposed method the calculated solar impedance data from experimental and simulation was compared with the measured EIS data. Impedance data is presented in three typical impedance formats; amplitude, phase, and complex plots in Fig. 13 to Fig. 15. These show the measured complex impedance of the PV panel from EIS measurement equipment (in blue), experimental test (in red dots), and simulation (in black).

The key result is that the on-line method of producing Impedance spectroscopy through the power electronics switching can give comparable results to off-line measurements under similar conditions and that circuit simulations using an equivalent circuit derived from these values performs in a similar manner. This means that the equivalent circuit parameters can be derived on-line and by tracking these it allows the impact of degradation to be observed in real time in a visual manner.

The experimental and simulation results appear noisy due to the non-linearity's in the circuit and the accuracy with which the parameters can be measured and calculated. This level of noise 
is of comparable order of magnitude to the off-line EIS equipment. Further work is needed to quantify the accuracy based on all the measurement and calculation errors.

operation at $\mathrm{A}$
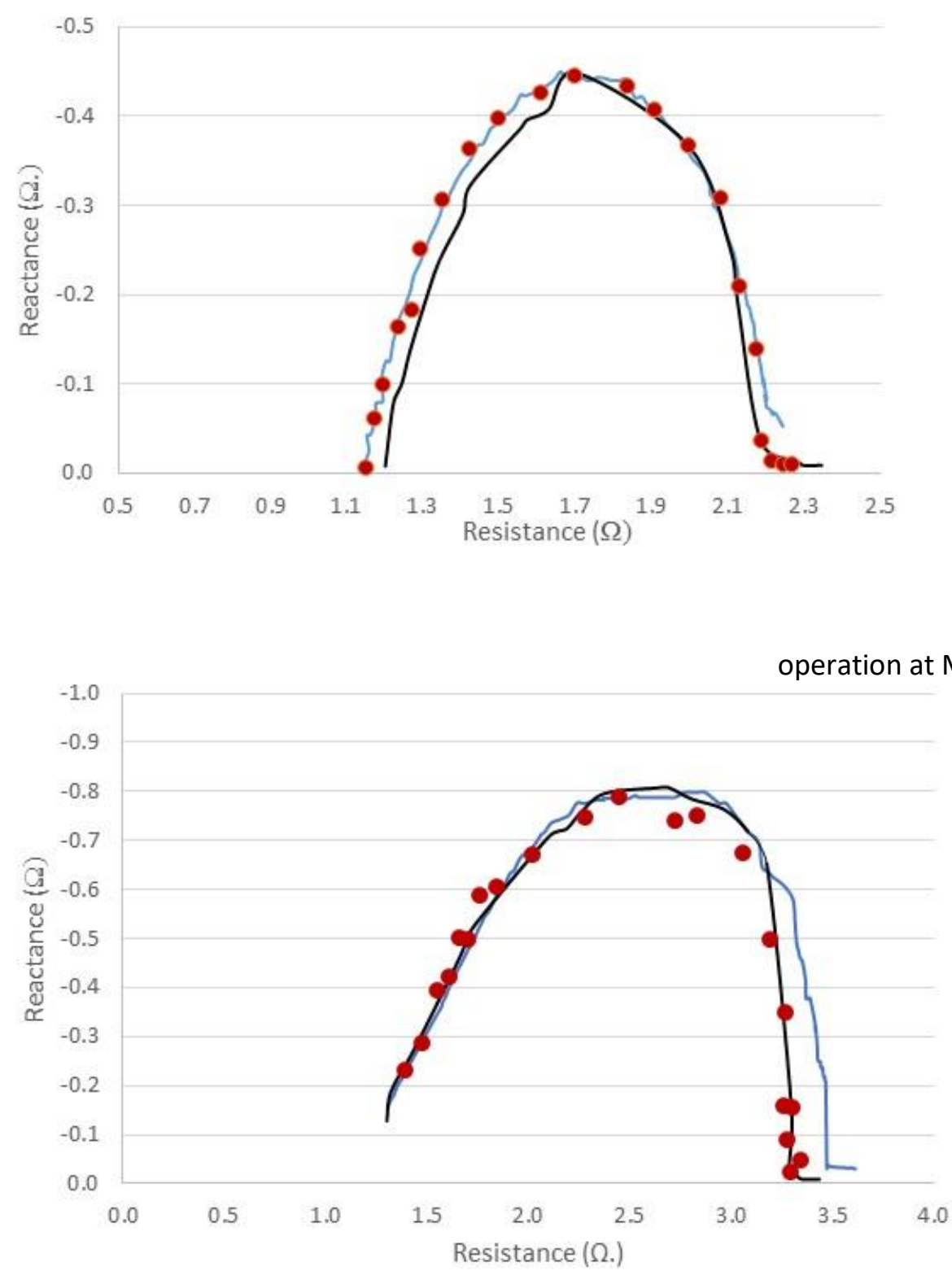

Fig. 13. Impedance Nyquist plot of solar panel with EIS (Blue), Simulation (Black), and Experimental Validation (Red dots) 

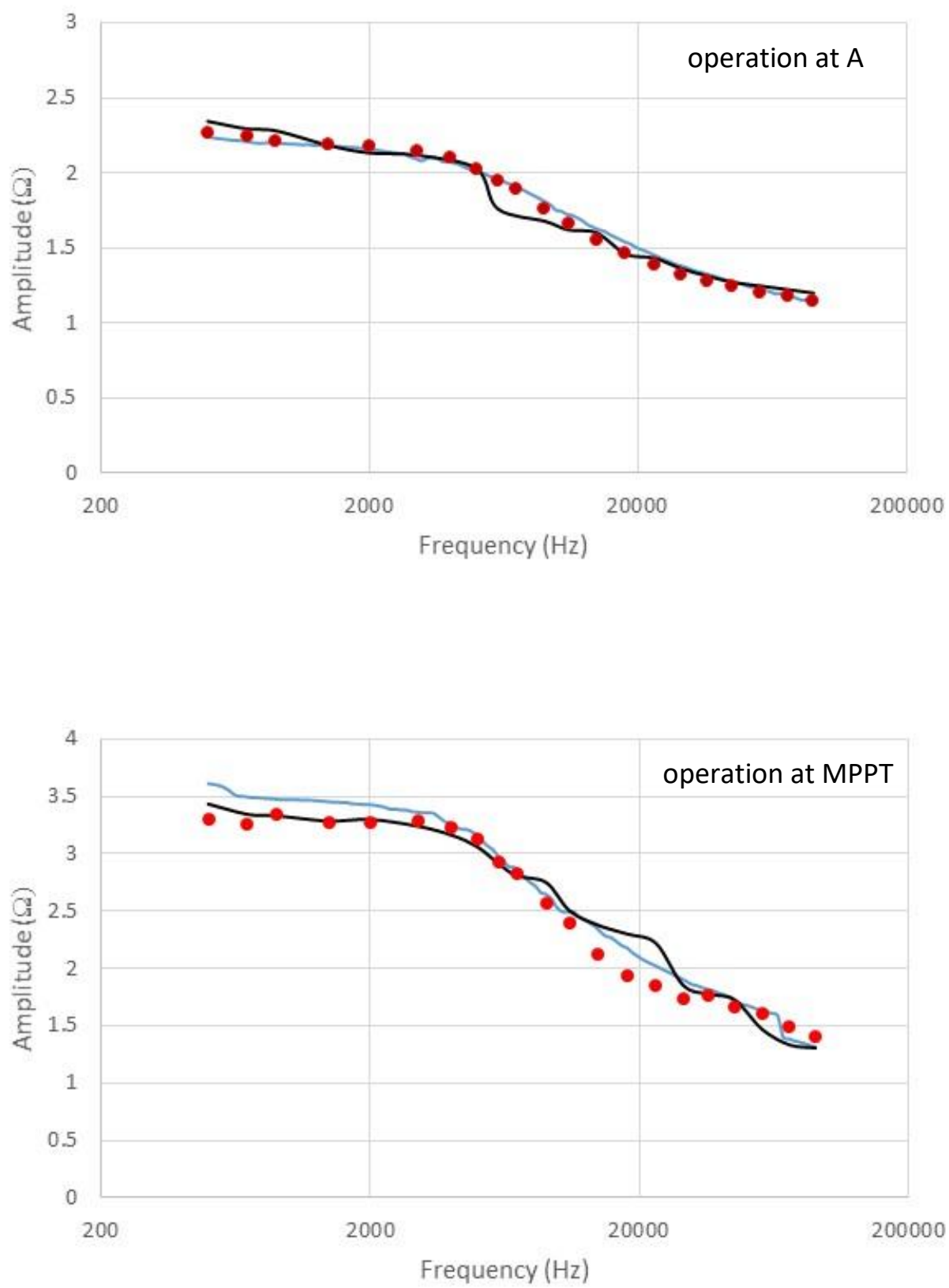

Fig. 14. Impedance amplitude bode plot EIS (Blue), Simulation (Black), and Experimental Validation (Red dots) 


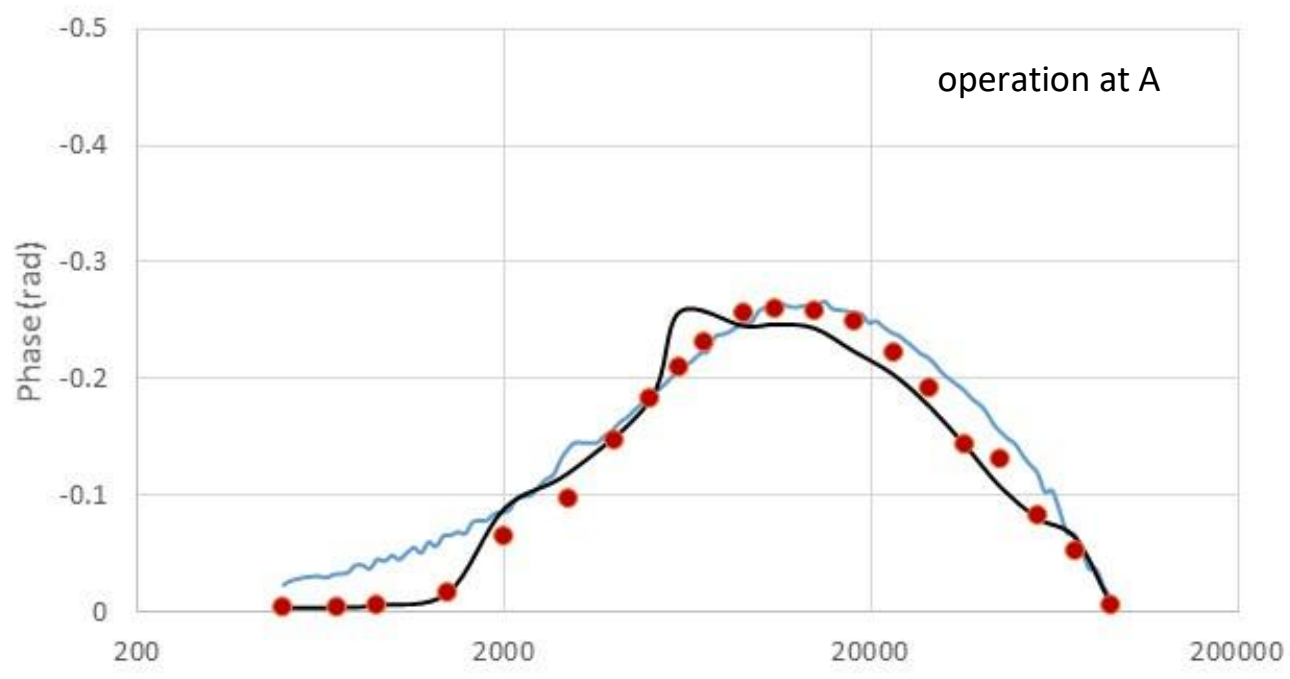

Frequency $(\mathrm{Hz})$

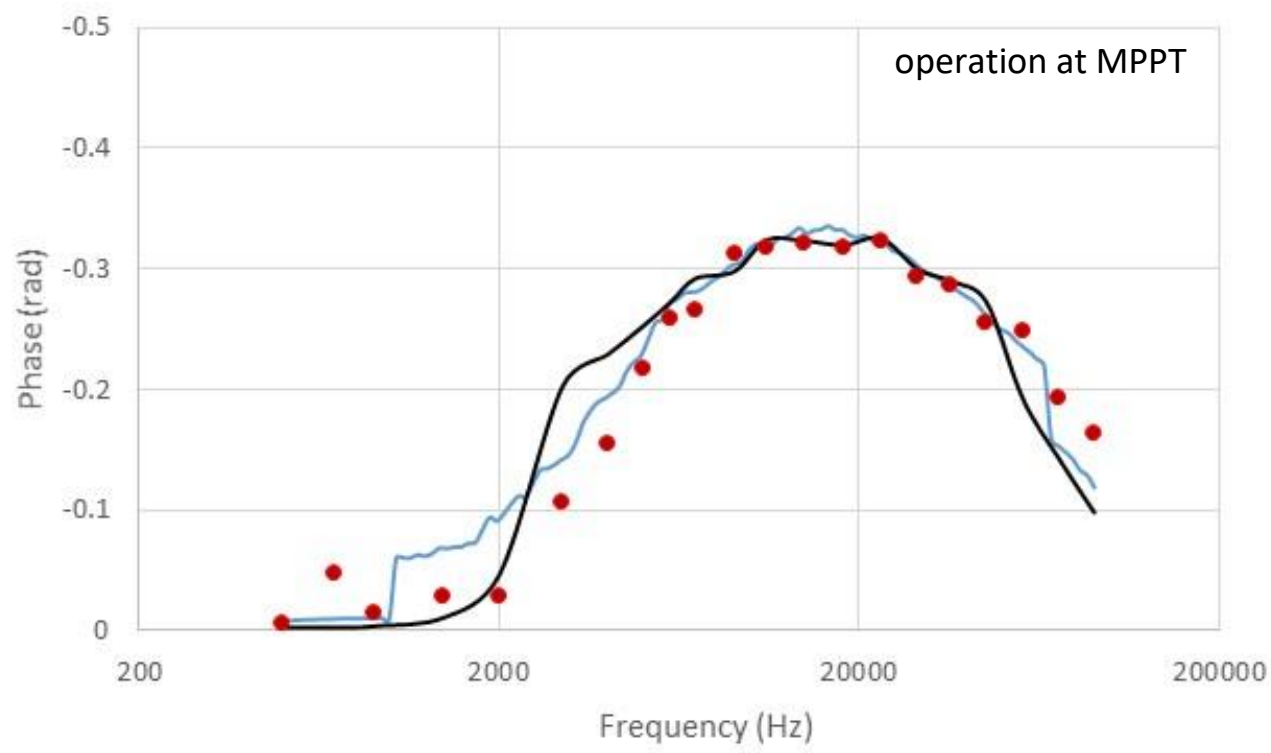

Fig. 15. Phase bode phase plot with EIS (Blue), Simulation (Black), and Experimental Validation (Red dots)

\section{Conclusion}


This paper presented an analysis of a method to extract the harmonic impedance of a solar panel under boost operation by varying the duty cycle around an average value designed to meet normal operation while at the same time adding a small harmonic component to allow on-line impedance estimation. The impact of the magnitude of that variation on the inductor and solar panel ripple current has been determined as an explicit expression. The methodology and variation of ripple current have been experimentally validated and a Nyquist and bode plots of a solar panel characteristic compared to EIS measurement have been produced while the solar panel was operating in boost mode. There is still much work to be done in this area including looking at the impact of the operating point of the solar panel on the low frequency harmonic and impedance measurement, determining the impact of discontinuous boost operation and the closed loop control for such a system including MPPT. However, this paper provides valuable insights into the trade-off in ripple current with convenient impedance measurement.

\section{ACKNOWLEDGMENT}

The authors would like to thank the EPSRC and Opal-RT for their contribution to this project.

\section{REFERENCES}

[1] E. Barsoukov and J. R. Macdonald, Impedance spectroscopy: theory, experiment, and applications: John Wiley \& Sons, $2^{\text {nd }}$ Edition, 2005.

[2] E. Parvazian, F. Karimzadeh, and M. Enayati, Photovoltaic Characterization and Electrochemical Impedance Spectroscopy Analysis of Dye-Sensitized Solar Cells Based on Composite TiO2-MWCNT Photoelectrodes, Journal of electronic materials, vol. 43, 2014, pp. 1450-1459.

[3] M. Shanmugam and M. F. Baroughi, Characterization of interfacial charge transport and recombination by impedance spectroscopy on $\mathrm{SiO} 2$ coated $\mathrm{TiO} 2$ based dye 
sensitized solar cells, in Photovoltaic Specialists Conference (PVSC), 2011 37th IEEE, 2011, pp. 002656-002660.

[4] H. Chin-Hui, C. Jung-Chuan, L. Yi-Hung, L. Yu-Jen, C. Chia-Ming, and N. Yu-Hsun, "Analysis of different dye-sensitized solar cell models by electrochemical impedance spectroscopy," in Electron Devices and Solid-State Circuits (EDSSC), 2015 IEEE International Conference on, 2015, pp. 29-32.

[5] S. Sarker, H. W. Seo, and D. M. Kim, Electrochemical impedance spectroscopy of dyesensitized solar cells with thermally degraded N719 loaded TiO 2, Chemical Physics Letters, vol. 585, 2013, pp. 193-197.

[6] A. Cester, N. Wrachien, M. Bon, G. Meneghesso, R. Bertani, R. Tagliaferro, et al., Degradation mechanisms of dye-sensitized solar cells: Light, bias and temperature effects, in Reliability Physics Symposium (IRPS), 2015 IEEE International, 2015, pp. 3E.2.1-3E.2.8.

[7] N. Kato, Y. Takeda, K. Higuchi, A. Takeichi, E. Sudo, H. Tanaka, et al., Degradation analysis of dye-sensitized solar cell module after long-term stability test under outdoor working condition, Solar Energy Materials and Solar Cells, vol. 93, 2009, pp. 893-897.

[8] M. Lohrasbi, P. Pattanapanishsawat, M. Isenberg, and S. S. C. Chuang, Degradation study of dye-sensitized solar cells by electrochemical impedance and FTIR spectroscopy, in Energytech, 2013 IEEE, 2013, pp. 1-4.

[9] D. A. Howey, P. D. Mitcheson, V. Yufit, G. J. Offer, and N. P. Brandon, Online Measurement of Impedance Using Motor Controller Excitation, Vehicular Technology, IEEE Transactions on, vol. 63, 2014, pp. 2557-2566.

[10] R. Koch, R. Kuhn, I. Zilberman, and A. Jossen, Electrochemical impedance spectroscopy for online battery monitoring - power electronics control, in Power Electronics and Applications (EPE'14-ECCE Europe), 2014 16th European Conference on,2014,pp.1-10. 
[11] H. Wangxin and J. A. Qahouq, An Online Battery Impedance Measurement Method Using DC-DC Power Converter Control, Industrial Electronics, IEEE Transactions on, vol. 61, 2014, pp. 5987-5995.

[12] M. A. Varnosfaderani; D. Strickland, Online impedance spectroscopy estimation of a battery, in Power Electronics and Applications (EPE'16-ECCE Europe), 2016 18th European Conference on,2016,pp.1-10

[13] F.R. Corner, Introductory Topics in Electronics and Telecommunications Modulation, Edward Arnold, $2^{\text {nd }}$ Edition, 1982, pp. 52-53.

[14] S. Armstrong, C. K. Lee and W. G. Hurley, "Investigation of the harmonic response of a photovoltaic system with a solar emulator," 2005 European Conference on Power Electronics and Applications, Dresden, 2005, pp. 8 pp.-P.8.

[15] A. Lasia, Electrochemical impedance spectroscopy and its applications, in Modern aspects of electrochemistry, ed: Springer, 2002, pp. 143-248.

[16] B. Romero, G. d. Pozo, B. Arredondo, J. P. Reinhardt, M. Sessler, W. U, et al., Circuital Model Validation for S-Shaped Organic Solar Cells by Means of Impedance Spectroscopy, IEEE Journal of Photovoltaics, vol. 5, 2015, pp. 234-237. 